\title{
Penerapan Total Productive Maintenance (TPM) Produksi Dengan Metode Overall Equipment Effectiveness (OEE) Pada Proses Produksi Botol (PT. XY Pandaan - Pasuruan)
}

\author{
Abdul Wahid \\ Jurusan Teknik Industri Fakultas TeknikUniversitas Yudharta Pasuruan \\ Email : wahid@yudharta.ac.id
}

\begin{abstract}
Abstrak
Peranan mesin sangat vital pada seluruh proses produksi, sehingga keadaan mesin harus selalu dalam keadaan yang optimal, terutama mesin Krones karena pada mesin ini terjadi proses perubahan preform menjadi botol. Tingginya waktu downtimeakan berpengaruh terhadap target produksi yang sering tidak tercapai. Pengukuran nilai efisiensi ini hanya memperhatikan target produksi. Untuk mengetahui efisiensi dari mesin perlu adanya aspek availability, performance, dan quality.Kegiatan perawatan mengalami perkembangan seiring perkembangan ilmu pengetahuandan teknologi menjadi Total Productive Maintenance (TPM).Tujuan dari TPM adalah melakukan minimalisasi kerugian dari sistem manufaktur sehingga mengurangi biaya produksi dengan melakukan pendekatan Overal Equipment Effectiveness $(O E E)$.Perhitungan nilai OEE mempertimbangkan aspek availability, perfomance, dan quality.Selain itu, untuk mengetahui besarnya kerugian produksi, maka dilakukan analisis terhadap six big losses yang pada dasarnya merupakan kerugian dari ketiga aspek OEE.Dengan analisis ini, nantinya dapat diketahui akar penyebab masalah-masalah yang terjadi pada mesin Krones sehingga dapat dilakukan langkah perbaikan. Tujuan dari Penelitian di PT XY Pandaan adalah menghitung OEE dari mesin Krones, menentukan six big losses, dan mencari penyebab masalah dengan fishbonedan melakukan proses perbaikan.
\end{abstract}

Kata Kunci : Overall Equipment Effectiveness, Six Big Losses, Total Productive Maintenance.

\section{Pendahuluan}

Perkembangan dunia industri di Indonesia dalam beberapa periode terakhir cukup mengalami peningkatan yang signifikan di bidang kualitas dan productive maintenance[1]. Dunia industri telah menuju ke arah peningkatan efektifitas dan efesiensi di mana perusahaan dituntut untuk bekerja cepat tetapi tetap harus dapat menghasilkan produk dengan kualitas yang baik [2][3]. Efektifitas dan efisiensi dalam suatu perusahaan dapat meningkatkan profit yang diterima perusahaan serta meminimalisasi pengeluaran biaya produksi [4]. Selain itu, untuk melakukan peningkatan produktivitas mesin maka pengelolaan keputusan atau kebijakan maintenance harus tepat[4][5][6]. Sistem perawatan yang dilakukan mesin Krones, yang dilakukan oleh PT. XY Pandaan adalah dengan melakukan langkah preventif maintenance, yaitu melakukan scouring dan dengan menggunakan kebijakan repair, yaitu perawatan yang dilakukan dengan mengganti bagian part yang rusak, serta dengan melakukan overhaul kepada sebuah mesin setiap lima tahun sekali. Untuk meminimalisasi biaya produksi, tentunya diperlukan pengambilan keputusan maintenance mesin yang tepat [6]. Pengambilan keputusan dilakukan dengan membandingkan kebijakan mana yang lebih baik antara kebijakan preventive maintenance dan kebijakan repair maintenance[5].

Dengan adanya masalah ini, maka perlu dilakukan analisis dengan menggunakan pendekatan Overall Equipment Effectiveness dan pembuatan kebijakan maintenance yang terbaik sehingga diharapkan produktivitas mesin krones menjadi meningkat. Dengan analisis ini, nantinya dapat 
diketahui akar penyebab masalah-masalah yang terjadi pada mesin krones sehingga dapat dilakukan langkah perbaikan dan mengetahui kebijakan maintenance yang tepat masalah sehingga produktivitas mesin menjadi optimal dengan biaya produksi yang lebih murah.

OEE adalah suatu cara untuk mengukur kinerja mesin produksi dalam penerapan program Total ProductiveMaintenance (TPM) Pengukuran Kinerja dengan Overall Equipment Effectiveness (OEE) terdiri dari 3 komponen utama pada mesin produksi yaitu Availability (Waktu Kesediaan Mesin), Performance (Jumlah unit yang diproduksi) dan Quality (Mutu yang dihasilkan). Dari hasil komperasi secara teoritis beberapa metode diatas dan hasil studi pendahuluan dilapangan metode yang digunakan peneliti untuk pengukuran performa di PT XY Pandaan adalah Overall Equipment Effectiveness (OEE) sebagai objek pengukuran efektifitas peralatan secara keseluruhan sebagai dasar untuk melaksanakan kegiatan implementasi Total Productive Maintenance (TPM) [4][5][6][7].

PerhitunganOveralEquipment Effectiveness ( OEE)

Setiap perusahaan menginginkan peralatan dapat bekerja secara maksimal, tidak ada waktu yang terbuang, tetapi kenyataannya hal tersebut tidaklah mudah.Untuk itu maka pengukuran terhadap Overall Equipment Effectiveness sangatlah diperlukan. Tabel 1 menjelaskan batasan penentuan nilai-nilai OEE yang ideal dengan standar industri World Class:

Tabel 1 Nilai-nilai OEE yang Ideal

\begin{tabular}{|c|c|}
\hline Deskripsi & Nilai \\
\hline Availability & $>90 \%$ \\
\hline Performance Efficiency & $>95 \%$ \\
\hline Quality Rate & $>99 \%$ \\
\hline OEE & $>85 \%$ \\
\hline
\end{tabular}

Overall Equipment Effectiveness (OEE) adalah sebuah matrix yang berfokus pada seberapa efetif suatu operasi produksi dijalankan.Hasil dinyatakan dalam bentuk yang bersifat umum sehingga memungkinkan perbandingan antara unit manufaktur di industri yang berbeda.Overall Equipment Effectiveness $(O E E)$ adalah tingkat keefektifitas fasilitas secara menyeluruh yang diperoleh dengan memperhitungkan availability, performancerate dan quality rate.OEE didapatkan melalui persamaan berikut $: \mathrm{OEE}=$ Quality (\%) $\mathrm{x}$ Performance (\%) $\mathrm{x}$ Availability (\%).

\section{Metode Penelitian}

Alur dari penelitian ini dimulai dari studi liberatur dan survey ke perusahaan.Berdasarkan hasil yang didapat dari survey kemudian dibuat perumusan masalah dan tujuan penelitian.Setelah itu dilakukan pengumpulan data yang dibutuhkan untuk penelitian.Data yang digunakan terdiri dari dua jenis yaitu data primer dan sekunder.Data primer berupa wawancara dan observasi sedangkan data sekunder berasal dari data perusahaan.Setelah data yang dibutuhkan terkumpul kemudian dilakukan perhitungan OEE, diagram fishbone dan hasil perbaikan.

Untuk mengetahui tingkat efektifitas dari sebuah mesin maka dapat dilakukan penerapan konsep Total ProductiveMaintenance (TPM) dengan menggunakanmetode Overall Equipment Effectiveness (OEE) [8].Dari dua jenis data yang di ambil penulis mencoba membandingkan nilai Overall Equipment Effectiveness (OEE) pada Line Krones PT. XY Pandaan dengannilai OEE standart dunia yaitu $85 \%$ dan mencari kebijakan maintenance yang terbaik, yaitu dengan repair policy atau dengan preventivemaintenance. 
Untuk menghitung nilai OEE maka perlu diketahui nilai masing-masing komponen tersebut.

\section{Availability}

Availability adalah suatu rasio yang menunjukkan waktu yang tersedia untuk mengoperasikan mesin.Availability merupakan perbandingan antara waktu operasi mesin actual dengan waktu yang operasi mesin yang telah direncanakan.Semakin tinggi nilai availabilitynya maka semakin baik.Standar untuk nilai availability yang ditetapkan perusahaan adalah 98\%.Berikut adalah hasil perhitungan availability.

\section{Performance Rate}

Performance rate mempertimbangkan faktor yang menyebabkan proses produksi tidak sesuai dengan kecepatan maksimum yang seharusnya ketika di operasikan. Performance rate yang diharapkan perusahaan yaitu tidak ada penurunan kecepatan mesin standart dibandingkan dengan aktual. Standar untuk nilai performance rate adalah 100\%. Hasil perhitungan performance rate di bulan September 2019 adalah sebagai berikut

\section{Quality Rate}

Quality rate merupakan perbandingan antara produk yang lolos quality control dengan total produksi.Pada perusahaan ini, produk yang lolos quality control disebut dengan produk ok. Sedangkan produk yang tidak lolos quality control disebut dengan produk reject dan pending karena produk tersebut akan langsung diperbaiki dengan dilakukan sortir. Apabila sudah lolos quality control maka produk siap untuk diserahkan ke gudang. Perusahaan sendiri telah memberikan target produk yang masuk dalam kategori ok adalah sebesar 98.5\%.

\section{Analisis Overall equipment effectiveness}

Perhitungan Overall equipment effectiveness bertujuan untuk mengetahui tingkat ke efektifan suatu mesin atau suatu line produksi.Dalam penelitian ini perhitungan OEE bertujuan untuk mengetahui tingkat keefektifan mesin krones.Overall equipment effectiveness mempertimbangkan waktu, kualitas, dan performa dari line produksi. Berikut ini merupakan faktor penyebab produktivitas mesin Krones yang kurang maksimal dijelaskan dengan menggunakan diagram sebab akibat pada gambar 1 .

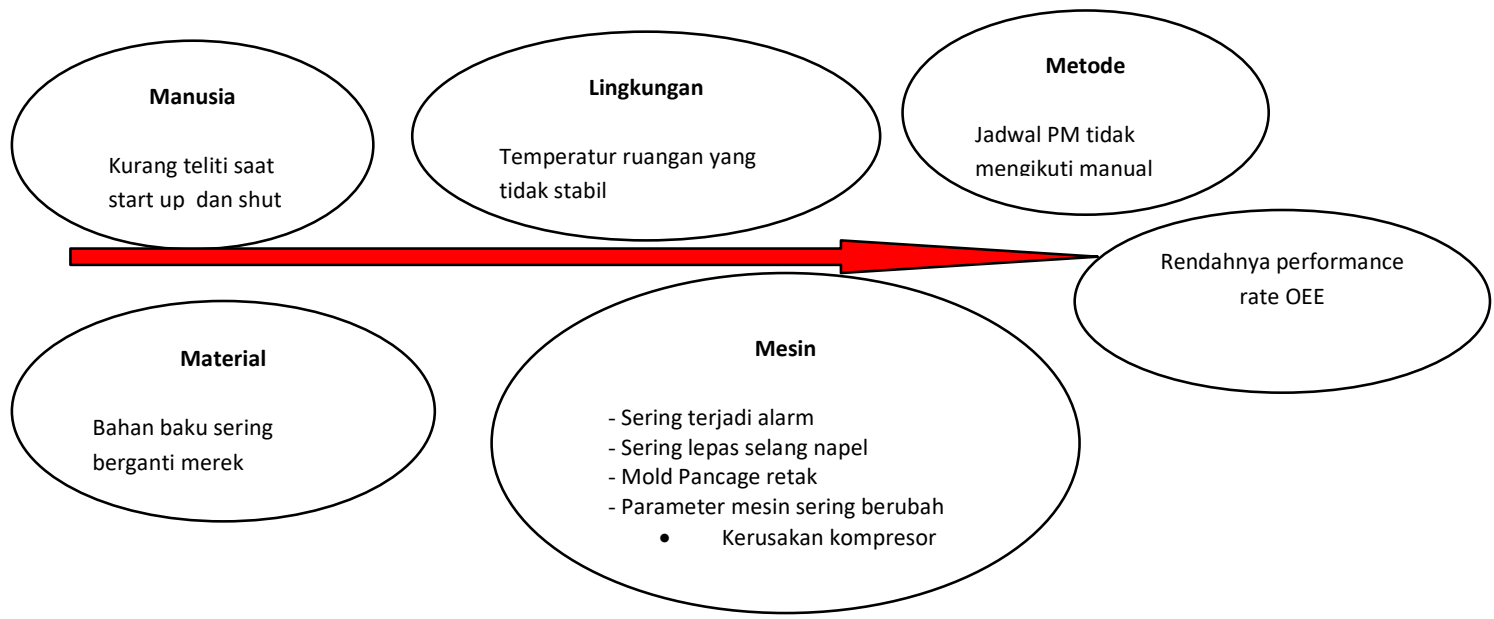

Gambar. 1 Diagram sebab akibat

\section{Hasil dan Pembahasan}

Setelah dilakukan analisa dengan menggunakan fishbone diagram dapat diketahui bahwa terdapat lima faktor yang menjadi penyebabnya yaitu faktor manusia, faktor material, faktor mesin, faktor metode dan faktor lingkungan. Faktor material berhubungan dengan gudang dan produksi. Quality 
incoming dapat menginformasikan certificate of analysis (COA) yang berisi data karakteristik material sehingga pada waktu proses produksi parameter setting dapat menyesuaikan. Operator produksi juga dapat menyimpan hasil dari parameter setting pada CPU yang terdapat pada mesin sehingga saat terjadi pergantian material tinggal menerapkan parameter setting yang sudah tersimpan. Start up dan shut down mesin menjadi sangat berpengaruh terhadap performa mesin keseluruhan ketika operator kurang teliti. Penggunaan lubricant plastik dapat mengurangi cacat produk saat proses start up mesin. Setting temperatur mesin pada suhu rendah $110{ }^{\circ} \mathrm{C}$ saat awal start juga berpengaruh untuk mengurangi cacat produk awal start, menambahkan parameter tersebut dalam instruksi kerja dan disosialisasikan ke seluruh operator sangat disarankan. Metode maintenance yang digunakan oleh perusahaan saat ini adalah preventive maintenance yang berdasarkan hour meter mesin. Jadwal produksi yang tidak menentu menyebabkan jadwal perawatan yang tidak menentu juga. Sebaiknya ada komunikasi terjawal dari pihak PPIC baik melalui email atau pertemuan rutin terjadwal agar dapat menentukan kapan waktu preventivemaintenance dilakukan.

Area mesin yang bersih sangat berpengaruh terhadap kinerja mesin keseluruhan. Untuk memastikan lingkungan selalu bersih diperlukan penanggungjawab area untuk menjaga kondisi mesin secara keseluruhan. Audit 5S dan GMP menjadi penting untuk memastikan kondisi dan penilaian terhadap area kerja yang bersih dan nyaman. Kondisi suhu ruang yang menyebabkan temperature preform tidak stabil dapat diatasi dengan perawatan AC secara berkala.

Ideal speed yang stabil sesuai standart yang ditetapkan perusahaan 16800 botol per hour (BPH) sangat penting dan berpengaruh terhadap performance rate pada Overall equipment effectiveness. Ketersediaan suku cadang mesin juga sangat penting, perkiraan penggantian suku cadang dijadwalkan sesuai buku panduan mesin sehingga order dapat disesuaikan dan tidak menjadikan stock mati yang dapat menambah biaya perusahaan. Menyimpan hasil parameter setting pada mesin sangat disarankan sehingga ketika terjadi perubahan dimensi maupun berat dapat memangil ulang paramater setting yang sesuai.

Hasil perhitungan nilai Overall Equipment Effectiveness (OEE) secara keseluruhan pada bulan Januari sampai dengan Juni 2019 yang dilihat dari aspek availabitlity, performance, quality.

\section{Utilisasi dan Hasil OEE}

Utilitas adalah kemampuan suatu mesin untuk menghasilkan suatu produk. Dan dapat dirumuskan sebagai berikut:

Utilitas $=\frac{\text { Produksi }}{\text { Kapasitas }}$
OEE $=$ Quality $x$ Performance $x$ Availability
Tabel 11 Hasil Perhitungan Utilisasi
\begin{tabular}{|l|l|c|c|c|}
\hline Machine & \multicolumn{1}{|c}{ Product } & Capacity & Target & Utilization \\
\hline Krones \#1 & Botol HF 350 ml Ftea & 10.276 .308 & 5.353 .824 & $52.10 \%$ \\
\hline Krones \#2 & Botol HF 350 ml Stea & 10.276 .308 & 1.407 .000 & $13.70 \%$ \\
\hline Krones \#3 & Botol HF 500 ml Sosro & 10.276 .308 & 880.824 & $8.57 \%$ \\
\hline
\end{tabular}

Sumber : Laporan Produksi September 2019

Tabel 12 Hasil Perhitungan OEE

\begin{tabular}{|c|c|c|c|c|c|c|}
\hline Utilization & Quality & Reject & Pending & Performance & Availability & OEE \\
\hline $52.10 \%$ & $99.95 \%$ & $0,05 \%$ & $0 \%$ & $100 \%$ & $99.37 \%$ & $99.32 \%$ \\
\hline
\end{tabular}


Jurnal Teknologi dan Manajemen Industri, Vol. 6 No. 1, Februari 2020

Pascasarjana Institut Teknologi Nasional Malang

\begin{tabular}{|c|c|c|c|c|c|c|}
\hline $13.70 \%$ & $99.51 \%$ & $0,18 \%$ & $0.31 \%$ & $100 \%$ & $95.67 \%$ & $95.20 \%$ \\
\hline $8.57 \%$ & $99.61 \%$ & $0.39 \%$ & $0 \%$ & $100 \%$ & $97.90 \%$ & $97.52 \%$ \\
\hline
\end{tabular}

Sumber : Laporan Produksi September 2019

\section{Kesimpulan}

Berdasarkan penelitian yang telah dilakukan, maka dapatkan kesimpulan sebagai berikut:

1. Berdasarkan pengamatan yang dilakukan dilapangan dengan metode time study, waktu yang dibutuhkan untuk membuat sebuah produk Botol adalah $16.800 \mathrm{pcs} / \mathrm{jam}$.

2. Berdasarkan data hasil produksi bulan September 2019 pada departemen Botol. Kapasitas untuk mesin Krones Botol HF $350 \mathrm{ml}$ Ftea adalah 10.276.308 produk per bulan, Botol HF $350 \mathrm{ml}$ Stea adalah 10.276.308 produk per bulan dan Botol HF $500 \mathrm{ml}$ Sosro adalah 10.276.308 Produk. Hasil perhitungan Overall Effectiveness Equipment (OEE) menunjukkan mesin Krones produksi Botol HF 350 ml Ftea menghasilkan OEE 99.32\%, Botol HF 350 ml Stea menghasilkan OEE 95.20\%, sedangkan Botol HF $500 \mathrm{ml}$ Sosro menghasilkan OEE 97.52\%. Dari data tersebut terdapat perbedaan yang signifikan terkait availability Botol HF $350 \mathrm{ml}$ Ftea, Botol HF $350 \mathrm{ml}$ Stea dan Botol HF $500 \mathrm{ml}$ Sosro, dimana Botol HF $350 \mathrm{ml}$ Stea mempunyai availability yang lebih rendah, ini mengindikasikan mesin Krones 2 lebih banyak mengalami break down. Sedangkan untuk performance mesin Krones 1 lebih tinggi dibandingkan dengan mesin Krones 2 dan Krones 3 ini terkait dengan utilization di mesin Krones 1 yang lebih baik dengan banyaknya permintaan dari customer.

\section{Daftar Referensi}

[1] Andhi S, Lukman,2017. industry kemasan plastic punya potensi besar dukung pertumbuhan di berbagai sektor.

[2] Kho. 2016. Pengertian Diagram Pareto dan Cara Membuatnya. https://ilmumanajemenindustri.com/pengertian-diagram-pareto-dan-cara membuatnya/.Diakses pada tanggal 3 April 2019. Pukul 09.00 WIB

[3] Melani Anggraeni 2016, Evaluasi Efektivitas Mesin Creeper Hammer Mill dengan Pendekatan Total Productive Maintenance (Studi Kasus: Perusahaan Karet Remah di Lampung Selatan)

[4] Rahmad, 2012.Penerapan Overall Equipment Effectiveness (Oee) Dalam Implementasi Total Productive Maintenance (TPM) (Studi Kasus di Pabrik Gula PT. "Y".)

[5] Arifianto, Asyraf.,2018. Penerapan Total Productive Manintenance (TPM) Dengan Menggunakan Metode Overall Equipment Effectiveness.

[6] Dyah dan Nadia, 2014. Analisis Penerapan Total Productive Maintenance (TPM) Menggunakan Overall Equipment Efectiveness Dan Six Big Losses Pada Mesin Cavitec di PT. Essentra.

[7] IM Trimastria, 2019. Komposit Degradabel Polietilena Tereftalat dengan selulosa menggunakan reagen fenton $\left(\mathrm{H} 2 \mathrm{O} 2 / \mathrm{fe}^{2}\right)$, https://doi.org/10.24843/JCHEM.2019.v13.i02.p13

[8] S. Anil Kumar and N Suresh, 2009. Operations Management 